\title{
Aspirin decreases hepatocellular carcinoma risk in hepatitis $C$ virus carriers: a nationwide cohort study
}

\author{
Yen-Hsiang Liao ${ }^{1}$, Ren-Jun Hsu ${ }^{1,2}$, Tzu-Hwei Wang ${ }^{1,2}$, Chen-Ta Wu', Sheng-Yao Huang ${ }^{1}$, Chung-Y. Hsu', \\ Yuan-Chih Su ${ }^{4,5}$, Wen-Lin Hsu ${ }^{1,2}$ and Dai-Wei Liu ${ }^{1,2^{*}}$
}

\begin{abstract}
Background: Aspirin has been found to lower the occurrence rates of some cancers through the inhibition of the cyclooxygenase enzyme. For example, there is a well-known association between aspirin use and the occurrence of hepatocellular carcinoma (HCC) in hepatitis B virus (HBV) carriers. However, the association, if any, between aspirin use and HCC in hepatitis $\mathrm{C}$ virus (HCV) carriers is unknown. Therefore, this study compared the occurrence rates of HCC in HCV carriers treated with or without aspirin.

Methods: The participants in this retrospective cohort study consisted of people newly diagnosed with HCV in Taiwan from 2000 to 2012. Those who were treated with aspirin were defined as the control group, whereas those not treated with aspirin were defined as the comparison cohort. We used a 1:1 propensity score matching by age, sex, comorbidities, drugs, diagnosis year, and index year with covariate assessment.

Results: Our study sample consisted of 2980 aspirin-treated HCV carriers and 7771 non-aspirin-treated HCV carriers. After propensity score matching, each cohort consisted of 1911 HCV carriers. The adjusted hazard ratio (aHR) of $\mathrm{HCC}$ incidence in the aspirin users $(\mathrm{aHR}=0.56,95 \% \mathrm{Cl}=0.43-0.72, p<0.001)$ was significantly lower than that in the non-aspirin users. A Kaplan-Meier analysis showed that among the HCV carriers, the aspirin users had a lower cumulative incidence rate of HCC over the first 10 years of aspirin treatment $(p<0.0001)$.

Conclusions: The HCC incidence rate was lower in the aspirin-using HCV carriers than in the non- aspirin-using HCV carriers, indicating that the effects of aspirin might occur through inhibition of the cyclooxygenase enzyme pathway. Moreover, protection from HCC was provided by less than a year of aspirin treatment, while treatment with aspirin for 1 to 2 years exhibited the greatest protective effect. We therefore encourage aspirin treatment to prevent HCC in HCV carriers.
\end{abstract}

Keywords: Aspirin, Hepatitis C virus carrier, Hepatocellular carcinoma

\section{Background}

Hepatocellular carcinoma (HCC) is one of the most common malignant neoplasms in the world. The incidence of HCC has increased not only in the United States [1] but also in Taiwan [2]. Hepatitis B virus (HBV) infections, hepatitis C virus (HCV) infections, and alcoholic liver cirrhosis are the main risk factors for

\footnotetext{
* Correspondence: wuchentatzuchi@gmail.com

${ }^{1}$ Department of Radiation Oncology, Hualien Tzu Chi Hospital, Buddhist Tzu Chi Medical Foundation, Hualien, Taiwan

${ }^{2}$ School of Medicine, Tzu Chi University, Hualien, Taiwan

Full list of author information is available at the end of the article
}

HCC [3-5]. Chronic inflammation occurring through the COX-2 pathway is one of the most important process in the induction not only of liver cirrhosis but also of HCC [6].

Aspirin has been widely used as an analgesic and antiinflammatory drug. It also plays an important role in preventing cerebrovascular and cardiovascular thrombosis and even lowering the associated mortality, especially in diabetes mellitus patients [7-10]. Aspirin may also prevent the occurrence of some cancers, such as colorectal cancer [11-14], lung cancer [15], prostate cancer [16], and head and neck cancer [17], as well as

(c) The Author(s). 2020 Open Access This article is distributed under the terms of the Creative Commons Attribution 4.0 International License (http://creativecommons.org/licenses/by/4.0/), which permits unrestricted use, distribution, and reproduction in any medium, provided you give appropriate credit to the original author(s) and the source, provide a link to the Creative Commons license, and indicate if changes were made. The Creative Commons Public Domain Dedication waiver (http://creativecommons.org/publicdomain/zero/1.0/) applies to the data made available in this article, unless otherwise stated. 
HCC [18]. Its effects are likely due to the inhibition of the cyclooxygenase enzyme. Aspirin, therefore, prevents carcinogenesis, cell invasion, angiogenesis, and metastasis through its promotion of prostanoid synthesis [19]. It also induces apoptosis by altering the $\mathrm{Bax} / \mathrm{Bcl}-2$ ratio and activating death receptors [19].

After being infected with $\mathrm{HCV}$, a patient becomes an $\mathrm{HCV}$ carrier. Aspirin treatment can decrease the occurrence of HCC through the inhibition of the cyclooxygenase enzyme pathway. Some retrospective reports have shown that aspirin decreases the incidence of HCC $[18,20]$. However, the association between aspirin use and the incidence of HCC has been evaluated only in HBV carriers, not in HCV carriers [21].

Therefore, we conducted a nationwide cohort study to evaluate the association between aspirin use and the incidence rate of $\mathrm{HCC}$ in $\mathrm{HCV}$ carriers.

\section{Methods \\ Data sources}

We used the Longitudinal Health Insurance database 2000 (LHID2000) to conduct this cohort study. The LHID2000 is a sub-dataset of Taiwan's National Health Insurance Research Database (NHIRD) that contains 1 million random subjects. The NHIRD contains the medical care data from the National Health Insurance (NHI) program, which covers over $99 \%$ of the population of Taiwan. The NHIRD provides diagnosis data according to the International Classification of Diseases, 9th revision, Clinical Modification (ICD-9-CM), as well drug treatment and demographic information, with the identification of each individual included in the database being replaced by a random sequence. The Research Ethics Committee of China Medical University and Hospital in Taichung, Taiwan approved this study (CMUH104REC2-115(CR-2)).

\section{Study population}

The study population consisted of subjects who had been newly diagnosed with HCV (ICD-9-CM codes: 070.41, 070.44, 070.51, 070.54, and V02.62) from 2000 to 2012 and had at least two HCV outpatient records or one HCV inpatient record in the database. We then classified the study population of individuals diagnosed with $\mathrm{HCV}$ into aspirin users or non-aspirin users. The date on which aspirin was first received was defined as the index date. The exclusion criteria were as follows: (1) age less than 20 years, (2) HBV patient, (3) HIV infection, (4) treatment with an interferon or direct-acting anti-viral before the index date, and (5) a diagnosis of HCC before the index date. The aspirin users and nonaspirin users were matched using propensity score matching with gender, age, $\mathrm{HCV}$ diagnosis year, number of years of aspirin use, and interval between HCV diagnosis and aspirin use.

\section{Main outcome and confounding factors}

The main outcome of this study was a new diagnosis of HCC (ICD-9-CM code: 155). Each case of HCC was identified according to the records of the registry for catastrophic illness patients. If another disease occurred before the index date, it was considered as baseline comorbidity. These comorbidities included hypertension (ICD-9-CM codes: 401-405), diabetes mellitus (ICD-9CM code: 250), moderate or severe liver disease (ICD-9CM codes: 456.0-456.2, 572.2-572.4, 572.8), myocardial infarction (ICD-9-CM codes: 410, 412), congestive heart failure (ICD-9-CM codes: 398.91, 402.01, 402.11, 402.91, 404.01, 404.03, 404.13, 404.91, 404.93, 425.4, 425.5, 425.7 425.9, 428), and ischemic stroke (ICD-9-CM codes: 433-436). The use of medications such as antihypertensive agents, hypoglycemic agents, coumadin and heparin, other antithrombotic agents, and non-steroidal anti-inflammatory drugs (NSAIDs) within 180 days before the index date was considered a confounding factor.

\section{Statistical analysis}

We analyzed the HCC risk among the HCV carriers treated with aspirin and the HCV carriers not treated with aspirin. The follow-up period was the duration between the index date and the date of occurrence of the main outcome, withdrawal from the NHI program, death or the end of 2013, whichever came first. The crude, adjusted hazard ratios (aHRs) and corresponding 95\% confidence intervals (95\% CIs) were estimated using a Cox proportional hazards regression model without and with adjustment for gender, age, and confounding factors. We also assessed the aspirin effect among different strata of patient characteristics. We calculated the cumulative incidence of HCC using the Kaplan-Meier method and examined the difference in two trends using the log-rank test. All analyses were performed with the SAS statistical package, version 9.4 (SAS Institute, Cary NC). The significance level was set at 2-tail $p<0.05$.

\section{Results}

We documented 2980 aspirin users and 7771 nonaspirin users among the 16,466 individuals newly diagnosed as HCV carriers from 2000 to 2012 (Fig. 1). After applying the exclusion criteria to those patients, propensity score matching was applied to 2004 aspirin users and 4606 non-aspirin users. The final study population consisted of $1911 \mathrm{HCV}$ carriers treated with aspirin and 1911 HCV carriers not treated with aspirin. Table 1 shows that there were no significant differences between these aspirin-treated and non-aspirin-treated groups in terms of their gender, age, and baseline comorbidities. 


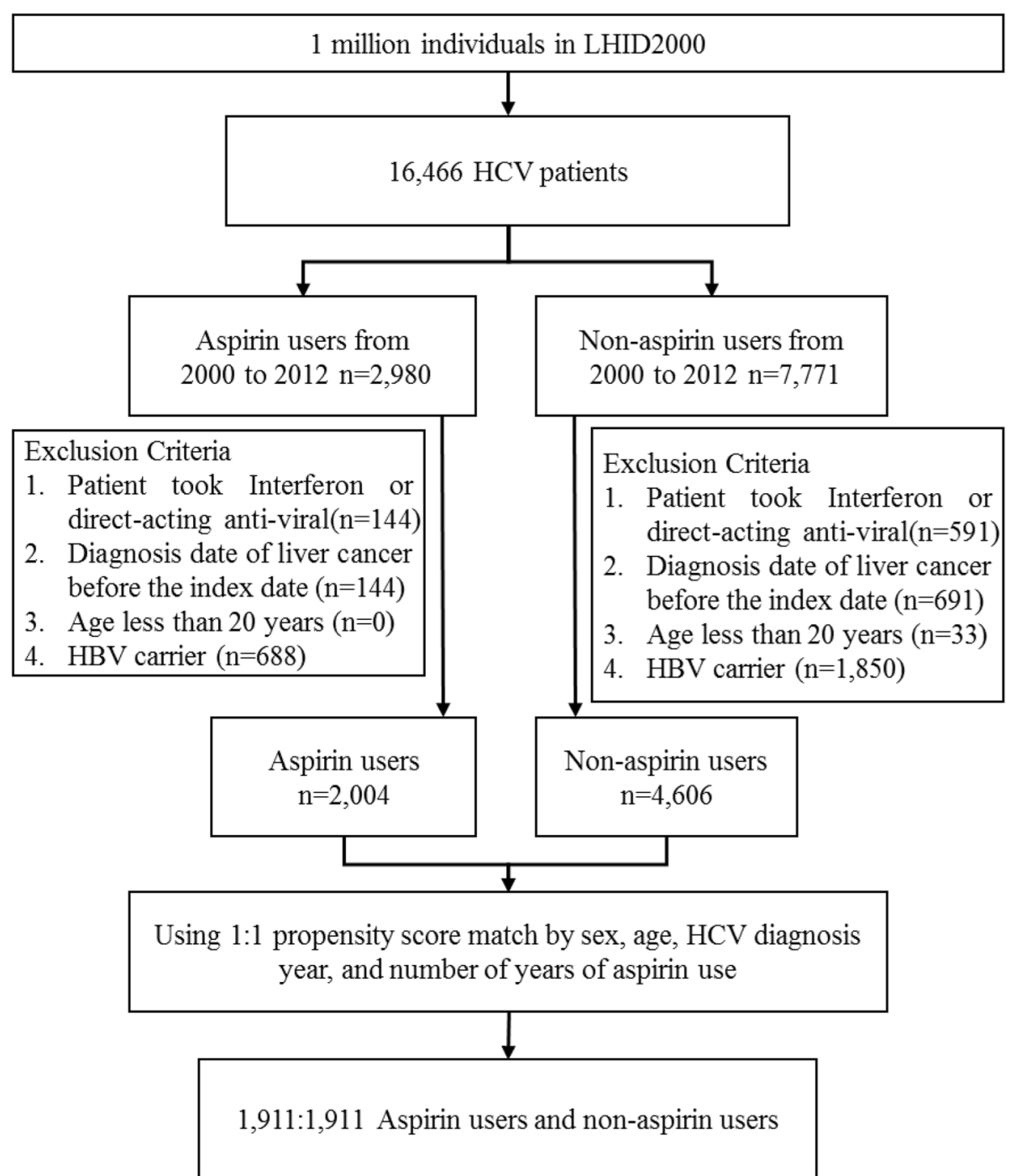

Fig. 1 Flow diagram of the selection of study subjects

However, the proportions of patients in the aspirintreated group who used antihypertensive agents, coumadin and heparin, antithrombotic agents, and NSAIDs were significantly greater than the proportions of patients in the non-aspirin-treated group who did so, although there was no significant difference between the two groups in terms of the proportions who used hypoglycemic agents.

Compared with the non-aspirin users, the aspirin users had a lower risk of HCC (adjusted HR $=0.56,95 \% \mathrm{CI}=$ $0.43-0.72, p<.001$; Table 2). The lower HCC risk in the aspirin users was further displayed by the cumulative HCC incidence trend (Fig. 2). Furthermore, Table 2 demonstrates a 1.71-fold higher HCC risk in the male patients than in the female patients (adjusted $H R=1.71$, $95 \% \mathrm{CI}=1.35-2.18, p<0.001)$. The HCC risk was also higher in those individuals who were older than 40 years than in those who were less than 40 years old. The comorbidities were not associated with the risk of $\mathrm{HCC}$ in the HCV carriers (that is, the risk of HCC in those individuals with a comorbidity was similar to that in those with no comorbidities). However, the adjusted HR in those who received anti-hypertensive agents was 1.94fold higher than the adjusted HR in those who did not (95\% CI $=1.45-2.6, p<0.001$; Table 2). Other medications were not associated with the risk of HCC.

Table 3 shows that aspirin use significantly decreased the risk of $\mathrm{HCC}$ in both genders (female: adjusted $\mathrm{HR}=$ $0.51,95 \% \mathrm{CI}=0.35-0.76, p<0.001$; male: adjusted $\mathrm{HR}=$ $0.59,95 \% \mathrm{CI}=0.42-0.83, p<0.01)$. However, with respect to patients in the same age strata, only the aspirin users who were 60 to 79 years old showed a significant 
Table 1 Demographic characteristics and covariates in HCV patients (carriers) treated with and without aspirin

\begin{tabular}{|c|c|c|c|c|c|}
\hline \multirow[t]{3}{*}{ Variables } & \multicolumn{4}{|c|}{ Aspirin } & \multirow[t]{3}{*}{$p$ value $^{*}$} \\
\hline & \multicolumn{2}{|c|}{$\begin{array}{l}\text { No } \\
(N=1911)\end{array}$} & \multicolumn{2}{|c|}{$\begin{array}{l}\text { Yes } \\
(N=1911)\end{array}$} & \\
\hline & $n$ & $\%$ & $n$ & $\%$ & \\
\hline Gender & & & & & 0.33 \\
\hline Female & 1027 & 53.7 & 997 & 52.2 & \\
\hline Male & 884 & 46.3 & 914 & 47.8 & \\
\hline Age, years & & & & & 0.01 \\
\hline$<40$ & 98 & 5.13 & 96 & 5.02 & \\
\hline $40-59$ & 606 & 31.7 & 580 & 30.4 & \\
\hline $60-79$ & 936 & 49.0 & 1025 & 53.6 & \\
\hline$\geq 80$ & 271 & 14.2 & 210 & 11.0 & \\
\hline Mean (SD) & 64.6 & 14.4 & 64.3 & 13.5 & $0.58^{\dagger}$ \\
\hline \multicolumn{6}{|l|}{ Baseline comorbidity } \\
\hline Hypertension & 1462 & 76.5 & 1410 & 73.8 & 0.05 \\
\hline Diabetes mellitus & 905 & 47.4 & 848 & 44.4 & 0.06 \\
\hline Moderate or severe liver disease & 34 & 1.78 & 23 & 1.2 & 0.14 \\
\hline Myocardial infarction & 123 & 6.44 & 133 & 6.96 & 0.52 \\
\hline Congestive heart failure & 431 & 22.6 & 429 & 22.5 & 0.94 \\
\hline Ischemic stroke & 1245 & 65.2 & 1212 & 63.4 & 0.27 \\
\hline \multicolumn{6}{|l|}{ Drugs } \\
\hline Anti-hypertensive agents & 1003 & 52.5 & 1506 & 78.8 & $<0.001$ \\
\hline Hypoglycemic agents & 114 & 5.97 & 141 & 7.38 & 0.08 \\
\hline Coumadin and heparin & 55 & 2.88 & 175 & 9.16 & $<0.001$ \\
\hline Other antithrombotic agents & 153 & 8.01 & 491 & 25.7 & $<0.001$ \\
\hline NSAIDs & 931 & 48.7 & 1140 & 59.7 & $<0.001$ \\
\hline
\end{tabular}

${ }^{*}$ Chi-square test; †Two sample t-test

Abbreviations: SD Standard deviation, NSAIDs Non-steroidal anti-inflammatory drugs

decrease in HCC risk compared to the non-aspirin users (adjusted $\mathrm{HR}=0.56,95 \% \mathrm{CI}=0.41-0.76, \quad p<0.001$ ). Among the anti-hypertensive agent users, meanwhile aspirin also had an apparent benefit of decreased HCC risk (adjusted HR $=0.53,95 \% \mathrm{CI}=0.4-0.71, p<0.001$ ).

For the aspirin users, we classified the duration of aspirin use into four levels $(<1$ year, $1-2$ years, $2-3$ years, $\geq 3$ years) while also classifying the non-users according to the same four levels for reference. Among the aspirin users, the most events occurred among those whose duration of aspirin use was less than 1 year (Table 4). Compared with the non-use of aspirin, all of the different durations of aspirin use had significant effects in terms of reducing $\mathrm{HCC}$ risk, except the duration of 2-3 years (adjusted $\mathrm{HR}=0.6,95 \% \mathrm{CI}=0.32-1.13, p=0.11$ ). The lowest adjusted $\mathrm{HR}$ was $0.33(95 \% \mathrm{CI}=0.18-0.61, p<$ 0.001 ), which was found for the aspirin users with a duration of aspirin use of $1-2$ years.

\section{Discussion}

Using a nationwide population database, we investigated the association between the use of aspirin and HCC risk in HCV carriers. This is the first study to find that HCV carriers who used aspirin had a lower risk of HCC than $\mathrm{HCV}$ carriers who did not use aspirin (adjusted $\mathrm{HR}=$ $0.56,95 \% \mathrm{CI}=0.43-0.72, p<0.001$; Table 2). Furthermore, the male $\mathrm{HCV}$ carriers had a 1.71-fold higher risk of $\mathrm{HCC}$ than the female $\mathrm{HCV}$ carriers (adjusted $\mathrm{HR}=$ $1.71,95 \% \mathrm{CI}=1.35-2.18, p<0.001$; Table 2 ), although aspirin treatment significantly reduced the HCC risk in both genders (female: adjusted $\mathrm{HR}=0.51,95 \% \mathrm{CI}=$ 0.35-0.76, $p<0.001$; male: adjusted HR $=0.59,95 \% \mathrm{CI}=$ $0.42-0.83, p<0.01$; Table 3). The Kaplan-Meier curves showed that the HCV carriers treated with aspirin had a lower cumulative incidence rate of HCC than those not treated with aspirin $(p<0.0001$; Fig. 2). In considering the duration of aspirin use, the lowest adjusted HR for developing $\mathrm{HCC}$ was 0.33 (95\% CI $=0.18-0.61, p<$ 0.001 ), which was found in those aspirin users with a duration of aspirin use of 1-2 years. Overall, the results of our study demonstrate that aspirin treatment can decrease the occurrence of $\mathrm{HCC}$ in $\mathrm{HCV}$ carriers.

Taiwan is one of the HBV endemic areas and has a substantial proportion of patients with dual HBV and $\mathrm{HCV}$ infection [22]. To prevent interference from HBV infections, we excluded HBV carriers in order to purify our study group. Since interferon or direct-acting antiviral treatment might totally cure an HCV infection [23], our study also excluded those patients who received interferon or direct-acting anti-viral treatment before the index date. This guaranteed that the investigated patients were $\mathrm{HCV}$ carriers while also ensuring that any lowering of the HCC occurrence was due only to the use of aspirin.

The HCC risk in the individuals with the comorbidity of hypertension was similar to that in those without hypertension. As shown in Table 2, the comorbidity of hypertension was not associated with an increased occurrence of HCC in our study population. It is interesting, however, to note that the HCC risk among participants receiving anti-hypertensive agents was 1.94fold higher than that among those not receiving such agents (95\% CI $=1.45-2.6, p<0.001$; Table 2). Although our present findings cannot explain this conflict, Ho et al. [24] found that the use of angiotensin-converting enzyme inhibitors and angiotensin II receptor blockers was associated with higher HCC occurrence in patient subgroups consisting of patients with no cirrhosis, no DM, and no hyperlipidemia. This issue requires further study in the future.

The real mechanism by which aspirin reduces HCC risk in $\mathrm{HCV}$ carriers is not well understood. A previous study, however, revealed different pathways for the viral 
Table 2 Cox model measured hazard ratios (HRs) and 95\% confidence intervals of HCC occurrence associated with and without aspirin use and covariates among HCV carriers

\begin{tabular}{|c|c|c|c|c|c|c|c|}
\hline \multirow[t]{2}{*}{ Characteristics } & \multirow{2}{*}{$\begin{array}{l}\text { Event no. } \\
(n=278)\end{array}$} & \multicolumn{3}{|c|}{ Crude } & \multicolumn{3}{|c|}{ Adjusted } \\
\hline & & $\mathrm{HR}$ & $(95 \% \mathrm{Cl})$ & $p$ value & $\mathrm{HR}$ & $(95 \% \mathrm{Cl})$ & $p$ value \\
\hline \multicolumn{8}{|l|}{ Aspirin } \\
\hline No & 147 & 1 & reference & & 1 & reference & \\
\hline Yes & 131 & 0.73 & $(0.58-0.93)$ & 0.01 & 0.56 & $(0.43-0.72)$ & $<0.001$ \\
\hline \multicolumn{8}{|l|}{ Gender } \\
\hline Female & 123 & 1 & reference & & 1 & reference & \\
\hline Male & 155 & 1.55 & $(1.23-1.97)$ & $<0.001$ & 1.71 & $(1.35-2.18)$ & $<0.001$ \\
\hline \multicolumn{8}{|l|}{ Age, years } \\
\hline$<40$ & 2 & 1 & reference & & 1 & reference & \\
\hline $40-59$ & 58 & 5.83 & $(1.42-23.87)$ & 0.01 & 5.42 & $(1.32-22.25)$ & 0.02 \\
\hline $60-79$ & 192 & 15.63 & $(3.88-63.02)$ & $<0.001$ & 13.45 & $(3.31-54.59)$ & $<0.001$ \\
\hline$\geq 80$ & 26 & 14.79 & $(3.5-62.56)$ & $<0.001$ & 12.24 & $(2.87-52.18)$ & $<0.001$ \\
\hline
\end{tabular}

Baseline comorbidity

Hypertension

No

Yes 208

1 reference

1.11

(0.85-1.46)

0.45

1

reference

Diabetes mellitus

$\begin{array}{ll}\text { No } & 169 \\ \text { Yes } & 109\end{array}$

reference

0.84

(0.66-1.06)

0.15

Moderate or severe liver disease

No $\quad 275$

1 reference

Yes

3

0.77

(0.25-2.39)

0.65

Myocardial infarction

No 269

Yes

1

reference

0.53

(0.27-1.03)

0.06

1

0.59

(0.3-1.15)

0.12

Congestive heart failure

No 230

1

reference

Yes

48

0.84

(0.61-1.15)

0.27

1

0.87

reference

Ischemic stroke

$\begin{array}{ll}\text { No } & 126 \\ \text { Yes } & 152\end{array}$

reference

0.86

(0.68-1.09)

0.21

0.83

reference

Drugs

Anti-hypertensive agents

$\begin{array}{ll}\text { No } & 75 \\ \text { Yes } & 203\end{array}$

reference

(1.47-2.5)

$<0.001$

1

1.94

reference

Hypoglycemic agents

$\begin{array}{ll}\text { No } & 265 \\ \text { Yes } & 13\end{array}$

reference

0.88

(0.51-1.54)

0.67

1

reference

0.61

$(0.29-1.28)$

0.19

1

0.52

reference

(0.24-1.11)

0.09 
Table 2 Cox model measured hazard ratios (HRs) and 95\% confidence intervals of HCC occurrence associated with and without aspirin use and covariates among HCV carriers (Continued)

\begin{tabular}{|c|c|c|c|c|c|c|c|}
\hline \multirow[t]{2}{*}{ Characteristics } & \multirow{2}{*}{$\begin{array}{l}\text { Event no. } \\
(n=278)\end{array}$} & \multicolumn{3}{|c|}{ Crude } & \multicolumn{3}{|c|}{ Adjusted } \\
\hline & & $\mathrm{HR}$ & $(95 \% \mathrm{Cl})$ & $p$ value & $\mathrm{HR}$ & $(95 \% \mathrm{Cl})$ & $p$ value \\
\hline \multicolumn{8}{|c|}{ Other antithrombotic agents } \\
\hline No & 232 & 1 & reference & & 1 & reference & \\
\hline Yes & 46 & 1.18 & $(0.86-1.62)$ & 0.30 & 1.06 & $(0.76-1.48)$ & 0.72 \\
\hline \multicolumn{8}{|l|}{ NSAIDs } \\
\hline No & 134 & 1 & reference & & 1 & reference & \\
\hline Yes & 144 & 0.83 & $(0.66-1.05)$ & 0.13 & 0.83 & $(0.65-1.05)$ & 0.12 \\
\hline
\end{tabular}

Abbreviations: HR Hazard ratio, Cl Confidence interval, NSAIDs Non-steroidal anti-inflammatory drugs

Adjusted HR: adjusted for gender, age, hypertension, diabetes mellitus, moderate or severe liver disease, myocardial infarction, congestive heart failure, ischemic stroke, anti-hypertension agents, hypoglycemic agents, coumadin and heparin, other antithrombotic agents and NSAIDs in Cox proportional hazards regression

and non-viral carcinogenesis of HCC. In an HBV transgenic mice model, it was found that platelets facilitate immune-mediated liver damage through the accumulation of HBV-specific cytotoxic T lymphocytes (CTLs) [25]. Sitia et al. [26] further found that aspirin decreased T-cell mediated inflammation, liver fibrosis, and progression to $\mathrm{HCC}$ in this $\mathrm{HBV}$ transgenic mice model. Whether the HBV-related carcinogenesis of HCC and the effect of aspirin on immunomodulation are the same as in HCV is still under investigation. However, aspirin has been found to have antioxidative and antiviral activity in $\mathrm{HCV}$-expressing cells through $\mathrm{Cu} / \mathrm{Zn}$ superoxide dismutase (SOD1) induction [27] and the downregulation of inducible nitric oxide synthase (iNOS) [28]. Moreover, Trujillo-Murillo et al. [29] found that acetylsalicylic acid decreases HCV replication via the inhibition of COX-2 expression through the activation of $\mathrm{p} 38$ and mitogen-activated protein kinase/extracellular signal-regulated kinase kinase 1/2 (MEK1/2). In a more recent study, Yin and Zhang [30] investigated the effects of aspirin on the blocking of HCV entry. They discovered that aspirin degrades claudin- 1 , an $\mathrm{HCV}$ receptor,

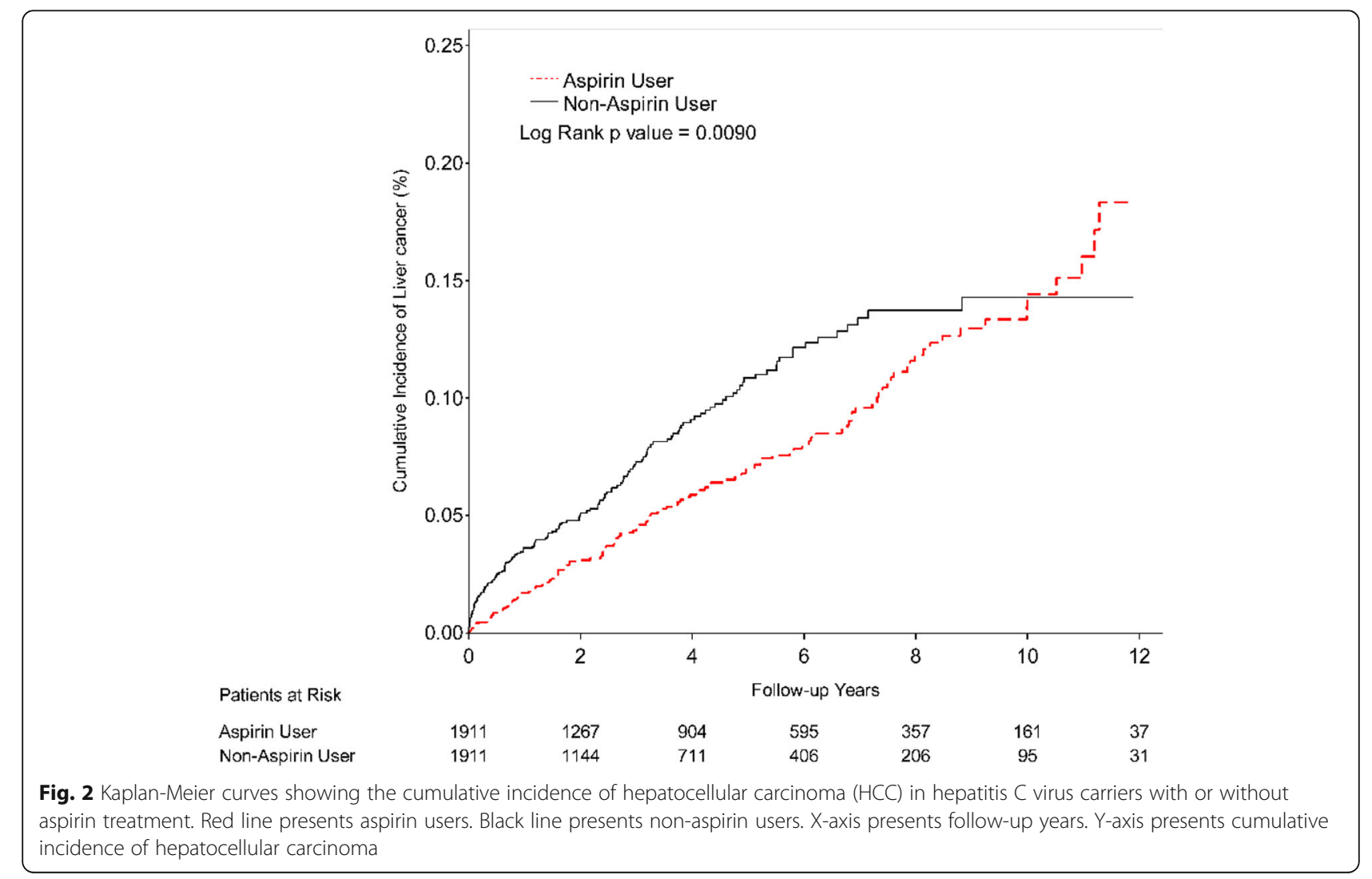


Table 3 Incidence rates, hazard ratios, and confidence intervals of HCC among different stratifications of HCV patients with and without aspirin use

\begin{tabular}{|c|c|c|c|c|c|c|c|c|}
\hline \multirow[t]{3}{*}{ Variables } & \multicolumn{6}{|c|}{ Aspirin } & \multicolumn{2}{|c|}{ Aspirin VS. Non-aspirin } \\
\hline & \multicolumn{3}{|c|}{$\begin{array}{l}\text { No } \\
(n=1911)\end{array}$} & \multicolumn{3}{|c|}{$\begin{array}{l}\text { Yes } \\
(n=1911)\end{array}$} & \multirow[t]{2}{*}{$\begin{array}{l}\text { Crude HR } \\
(95 \% \mathrm{Cl})\end{array}$} & \multirow[t]{2}{*}{$\begin{array}{l}\text { Adjusted HR } \\
(95 \% \mathrm{Cl})\end{array}$} \\
\hline & Event & Person years & $\mathbb{R}^{\dagger}$ & Event & Person years & $\mathbb{R}^{+}$ & & \\
\hline Overall & 147 & 6848 & 2.15 & 131 & 8546 & 1.53 & $0.73(0.58-0.93)^{* *}$ & $0.56(0.43-0.72)^{* * *}$ \\
\hline \multicolumn{9}{|l|}{ Gender } \\
\hline Female & 66 & 3838 & 1.72 & 57 & 4707 & 1.21 & $0.72(0.51-1.03)$ & $0.51(0.35-0.76)^{* * *}$ \\
\hline Male & 81 & 3010 & 2.69 & 74 & 3839 & 1.93 & $0.72(0.53-0.99)^{*}$ & $0.59(0.42-0.83)^{* *}$ \\
\hline \multicolumn{9}{|l|}{ Age, years } \\
\hline$<40$ & 0 & 592 & 0 & 2 & 633 & 0.32 & & \\
\hline $40-59$ & 31 & 2929 & 1.06 & 27 & 3069 & 0.88 & $0.83(0.5-1.39)$ & $0.64(0.35-1.14)$ \\
\hline $60-79$ & 98 & 2888 & 3.39 & 94 & 4325 & 2.17 & $0.65(0.49-0.87)^{* *}$ & $0.56(0.41-0.76)^{* * *}$ \\
\hline$\geq 80$ & 18 & 440 & 4.09 & 8 & 518 & 1.54 & $0.44(0.19-1.01)$ & $0.45(0.18-1.11)$ \\
\hline
\end{tabular}

Baseline comorbidity

Hypertension

\begin{tabular}{|c|c|c|c|c|c|c|c|c|}
\hline No & 39 & 1713 & 2.28 & 31 & 2557 & 1.21 & $0.55(0.34-0.88)^{*}$ & $0.39(0.23-0.65)^{* * *}$ \\
\hline Yes & 108 & 5135 & 2.1 & 100 & 5989 & 1.67 & $0.81(0.62-1.06)$ & $0.63(0.47-0.85)^{* *}$ \\
\hline
\end{tabular}

Diabetes mellitus

$\begin{array}{lllllllll}\text { No } & 90 & 3692 & 2.44 & 79 & 5060 & 1.56 & 0.65(0.48-0.88)^{* *} & 0.49(0.35-0.68)^{* * *} \\ \text { Yes } & 57 & 3156 & 1.81 & 52 & 3486 & 1.49 & 0.85(0.58-1.24) & 0.68(0.45-1.03)\end{array}$

Moderate or severe liver disease

$\begin{array}{lll}\text { No } & 145 & 6711\end{array}$

$\begin{array}{lll}\text { Yes } & 2 & 137\end{array}$

137

$2.16 \quad 130$

8468

1.54

1.46

78

1.28

Myocardial infarction

$\begin{array}{lll}\text { No } & 143 & 6443 \\ \text { Yes } & 4 & 405\end{array}$

405

Congestive heart failure

$\begin{array}{lll}\text { No } & 127 & 5443 \\ \text { Yes } & 20 & 1406\end{array}$

Ischemic stroke

$\begin{array}{lll}\text { No } & 66 & 2754 \\ \text { Yes } & 81 & 4094\end{array}$

2754

4094

Drugs

Anti-hypertensive agents

$\begin{array}{lll}\text { No } & 56 & 4333 \\ \text { Yes } & 91 & 2515\end{array}$

Hypoglycemic agents

$\begin{array}{lll}\text { No } & 141 & 6548 \\ \text { Yes } & 6 & 300\end{array}$

Coumadin and heparin

$\begin{array}{lll}\text { No } & 145 & 6765 \\ \text { Yes } & 2 & 83\end{array}$

Other antithrombotic agents

$\begin{array}{lll}\text { No } & 136 & 6531 \\ \text { Yes } & 11 & 318\end{array}$

318

$\begin{array}{ll}2.22 & 126 \\ 0.99 & 5 \\ & \\ 2.33 & 103 \\ 1.42 & 28 \\ & \\ 2.4 & 60 \\ 1.98 & 71\end{array}$

8057

489

1.56

1.02

6969

1577

1.48

1.78

3858

4688

1.56

1.51

$0.66(0.46-0.93)^{*}$

0.79(0.58-1.09)

$0.73(0.57-0.92)^{* *}$

$0.56(0.43-0.73)^{* * *}$

$0.8(0.07-8.85)$

$0.72(0.57-0.92)^{* *}$

$0.55(0.42-0.72)^{* * *}$

$1.02(0.27-3.82)$

$0.72(0.16-3.23)$

$0.65(0.5-0.84)^{* *}$

$1.25(0.7-2.23)$

$0.52(0.39-0.69)^{* * *}$

$0.79(0.42-1.5)$

Yes

11

$\begin{array}{ll}1.29 & 19 \\ 3.62 & 112\end{array}$

2189

6357

0.87

$0.69(0.41-1.16)$

0.58(0.33-1.01)

1.76

$0.51(0.38-0.67)^{* * *}$

$0.53(0.4-0.71)^{* * *}$

$\begin{array}{lllll}6548 & 2.15 & 124 & 8056 & 1.54\end{array}$

490

1.54

$0.73(0.57-0.93)^{*}$

$0.55(0.42-0.72)^{* * *}$

$2 \quad 7 \quad 490$

$0.65(0.21-2.03)$

$0.71(0.2-2.52)$

\begin{tabular}{|c|c|c|c|c|c|}
\hline 2.14 & 126 & 8037 & 1.57 & $0.75(0.59-0.95)^{*}$ & $0.56(0.43-0.73)^{* * *}$ \\
\hline 2.4 & 5 & 509 & 0.98 & $0.4(0.07-2.19)$ & $0.41(0.05-3.18)$ \\
\hline
\end{tabular}


Table 3 Incidence rates, hazard ratios, and confidence intervals of HCC among different stratifications of HCV patients with and without aspirin use (Continued)

\begin{tabular}{|c|c|c|c|c|c|c|c|c|}
\hline \multirow[t]{3}{*}{ Variables } & \multicolumn{6}{|l|}{ Aspirin } & \multicolumn{2}{|c|}{ Aspirin VS. Non-aspirin } \\
\hline & \multicolumn{3}{|c|}{$\begin{array}{l}\text { No } \\
(n=1911)\end{array}$} & \multicolumn{3}{|c|}{$\begin{array}{l}\text { Yes } \\
(n=1911)\end{array}$} & \multirow[t]{2}{*}{$\begin{array}{l}\text { Crude HR } \\
(95 \% \mathrm{Cl})\end{array}$} & \multirow[t]{2}{*}{$\begin{array}{l}\text { Adjusted HR } \\
(95 \% \mathrm{Cl})\end{array}$} \\
\hline & Event & Person years & $\mathbb{I R}^{\dagger}$ & Event & Person years & $\mathbb{I R}^{\dagger}$ & & \\
\hline \multicolumn{9}{|l|}{ NSAIDs } \\
\hline No & 69 & 3535 & 1.95 & 65 & 3108 & 2.09 & $1.07(0.76-1.5)$ & $0.79(0.54-1.14)$ \\
\hline Yes & 78 & 3313 & 2.35 & 66 & 5437 & 1.21 & $0.54(0.39-0.74)^{* * *}$ & $0.41(0.29-0.59)^{* * *}$ \\
\hline
\end{tabular}

Abbreviations: IRt Incidence rates, per 100 person-years, HR Hazard ratio, Cl Confidence interval, NSAIDs Non-steroidal anti-inflammatory drugs ${ }^{*} p<0.05,{ }^{* *} p<0.01,{ }^{* * *} p<0.001$

Adjusted HR: adjusted for gender, age, hypertension, diabetes mellitus, moderate or severe liver disease, myocardial infarction, congestive heart failure, ischemic stroke, anti-hypertension agents, hypoglycemic agents, coumadin and heparin, other antithrombotic agents and NSAIDs in Cox proportional hazards regression

through the proteasome degradation pathway and inhibits the entry of all genotypes of HCV pseudoparticles [30]. Taken together, past studies suggest that aspirin could reduce $\mathrm{HCV}$ expression and prevent $\mathrm{HCV}$ re-infection in patients with chronic HCV infection through COX-2dependent and COX-2-independent pathways [19].

We found that aspirin lowered the $\mathrm{HCC}$ incidence rate in $\mathrm{HCV}$ carriers over the first 10 years of aspirin treatment, including a $67 \%$ reduction in the occurrence rate in cases in which the duration of aspirin treatment was less than one year (Table 4; Fig. 2). Moreover, the cumulative $\mathrm{HCC}$ incidence rate became even lower over time. Our hypothesis is that aspirin could relieve chronic inflammation via the inhibition of the cyclooxygenase enzyme, thus lowering the occurrence of HCC at first [31, 32]. However, the inhibition of the cyclooxygenase enzyme also restrains the immune system, such that an HCV infection may become uncontrolled [33, 34]. Due to the resulting accumulation of liver cell damage and the duplication of $\mathrm{HCV}$, the $\mathrm{HCC}$ incidence rate then gradually becomes higher. Nonetheless, regular close follow-up visits and aspirin treatment might help lower the incidence rate of $\mathrm{HCC}$ in $\mathrm{HCV}$ carriers, especially over the first 10 years of aspirin treatment. That said, further clinical trials are warranted to clarify the preventive effects of aspirin against $\mathrm{HCC}$ risk in $\mathrm{HCV}$ carriers.
The present study, which was based on data from National Health Insurance program in Taiwan, had the following advantages: First, the large national sample population can be taken as representative of the entire population of Taiwan from 2000 to 2013; nearly all patients in Taiwan could get the proper medical care; and only a few people would take over-the-counter drugs themselves. Hence, we could retrieve the details of patients' information and medical records from the NHIRD. Second, cancers are categorized as serious diseases in Taiwan, such that cancer patients can apply for a "catastrophic illness card" as part of the NHI program. Most such patients' medical visits are free when they visit outpatient departments or are admitted to a hospital, and almost all cancer patients will receive medical treatment. The present study, therefore, could identify $\mathrm{HCV}$ carriers and HCC patients accurately. Third, we could rather precisely collect information for 16,466 HCC patients to perform a 1:1 propensity score matching by age, sex, comorbidities, drugs, treatment course of aspirin, and index year. Due to the gross sample size and detailed/accurate matching, we could then precisely analyze the association of aspirin use with HCC risk in the HCV carriers.

There were some limitations to this study. First, the study was a retrospective study. As such, we could not trace the HCV titer in these patients and thus could not

Table 4 The dose responses to aspirin among the HCV patients

\begin{tabular}{|c|c|c|c|c|c|c|c|}
\hline \multirow{2}{*}{$\begin{array}{l}\text { Duration of } \\
\text { aspirin use }\end{array}$} & \multirow{2}{*}{$\begin{array}{l}\text { Event no. } \\
(n=278)\end{array}$} & \multicolumn{3}{|c|}{ Crude } & \multicolumn{3}{|c|}{ Adjusted } \\
\hline & & $\overline{\mathrm{HR}}$ & $(95 \% \mathrm{Cl})$ & $p$ value & $\overline{\mathrm{HR}}$ & $(95 \% \mathrm{Cl})$ & $p$ value \\
\hline Non-user & 147 & 1 & reference & & 1 & reference & \\
\hline$<1$ year & 93 & 0.74 & $(0.57-0.96)$ & 0.02 & 0.63 & $(0.48-0.83)$ & $<0.001$ \\
\hline $1-2$ years & 12 & 0.52 & $(0.29-0.93)$ & 0.03 & 0.33 & $(0.18-0.61)$ & $<0.001$ \\
\hline $2-3$ years & 11 & 0.94 & $(0.51-1.73)$ & 0.84 & 0.6 & $(0.32-1.13)$ & 0.11 \\
\hline$\geq 3$ years & 15 & 0.8 & $(0.47-1.37)$ & 0.42 & 0.45 & $(0.26-0.79)$ & 0.005 \\
\hline
\end{tabular}

Abbreviations: HR Hazard ratio, CI Confidence interval, NSAIDs Non-steroidal anti-inflammatory drugs

Adjusted HR: adjusted for gender, age, hypertension, diabetes mellitus, moderate or severe liver disease, myocardial infarction, congestive heart failure, ischemic stroke, anti-hypertension agents, hypoglycemic agents, coumadin and heparin, other antithrombotic agents and NSAIDs in Cox proportional hazards regression 
prove our hypothesis that the $\mathrm{HCV}$ titer might flare up because of the restrained immune response owing to aspirin. Second, there were no data regarding the aspirin doses per day of the patients, because definite data in that regard were not included in the database. However, the prescribed dose in Taiwan is usually $100 \mathrm{mg}$ per day. Third, alcohol consumption also leads to a higher incidence of $\mathrm{HCC}$ among $\mathrm{HCV}$-infected individuals. However, the effects of alcohol consumption could not be measured in this retrospective study.

\section{Conclusion}

In conclusion, the use of aspirin appeared to reduce the risk of $\mathrm{HCC}$ in $\mathrm{HCV}$ carriers, with the hazard ratio of 0.56, $(95 \% \mathrm{CI}=0.43-0.72, p<0.001)$. Moreover, both genders exhibited significant reductions in the occurrence of HCC after aspirin use. Further clinical trials are warranted to clarify the preventive effects of aspirin against $\mathrm{HCC}$ risk in HCV carriers.

\section{Abbreviations \\ aHR: Adjusted hazard ratio; Cls: Confidence intervals; COX-2: Cyclooxygenase- 2; HBV: Hepatitis B virus; HCC: Hepatocellular carcinoma; HCV: Hepatitis C virus; NHI: National Health Insurance; NHIRD: National Health Insurance Research Database; NSAIDs: Non-steroidal anti-inflammatory drugs}

\section{Acknowledgements}

This work was supported by grants from the Ministry of Health and Welfare Taiwan (MOHW107-TDU-B-212-123004), China Medical University Hospital, Academia Sinica Stroke Biosignature Project (BM10701010021), MOST Clinical Trial Consortium for Stroke (MOST 106-2321-B-039-005).", Tseng-Lien Lin Foundation, Taichung, Taiwan and Katsuzo and Kiyo Aoshima Memorial Funds, Japan.

\section{Authors' contributions}

$Y L, R H, T W, C W$, and $W H$ set up the research project and finished the article. $\mathrm{DL}$ provided the research idea and checked the research outcomes. $\mathrm{SH}, \mathrm{CH}_{\text {, }}$ and YS provided and analyzed the data from the National Health Insurance program. All authors read and approved the final manuscript.

\section{Funding}

The authors received no specific funding for this work.

\section{Availability of data and materials}

The datasets used and analyzed during the current study are available from the corresponding author on reasonable request.

\section{Ethics approval and consent to participate}

This study was approved by the Institutional Review Board (IRB) of the China Medical University and Hospital (CMUH) Research Ethics Committee (REC) (IRB permit number: CMUH-104-REC2-115). Consent to participate was waived because this study was a retrospective database analysis.

\section{Consent for publication}

Not applicable.

\section{Competing interests}

The authors declare that they have no competing interests.

\section{Author details}

'Department of Radiation Oncology, Hualien Tzu Chi Hospital, Buddhist Tzu Chi Medical Foundation, Hualien, Taiwan. ${ }^{2}$ School of Medicine, Tzu Chi University, Hualien, Taiwan. ${ }^{3}$ Graduate Institute of Clinical Medical Science, China Medical University, Taichung, Taiwan. ${ }^{4}$ College of Medicine, China
Medical University, Taichung, Taiwan. ${ }^{5}$ Management Office for Health Data, China Medical University Hospital, Taichung, Taiwan.

Received: 1 September 2019 Accepted: 31 December 2019

Published online: 09 January 2020

\section{References}

1. Alter MJ, Margolis HS, Krawczynski K, et al. The natural history of community-acquired hepatitis $C$ in the United States. The sentinel counties chronic non-a, non-B hepatitis study team. N Engl J Med. 1992;327:1899905.

2. Su SY, Chiang CJ, Yang YW, Lee WC. Secular trends in liver cancer incidence from 1997 to 2014 in Taiwan and projection to 2035: an age-period-cohort analysis. J Formos Med Assoc. 2019;118:444-9.

3. Chen CJ, Liang KY, Chang AS, et al. Effects of hepatitis B virus, alcohol drinking, cigarette smoking and familial tendency on hepatocellular carcinoma. Hepatology. 1991;13:398-406.

4. Yeh MM, Daniel HD, Torbenson M. Hepatitis C-associated hepatocellular carcinomas in non-cirrhotic livers. Mod Pathol. 2009;23:276-83.

5. Degos F, Christidis C, Ganne-Carrie N, et al. Hepatitis C virus related cirrhosis: time to occurrence of hepatocellular carcinoma and death. Gut. 2000;47: $131-6$.

6. Cheng AS, Chan HL, Leung WK, et al. Expression of HBx and COX-2 in chronic hepatitis B, cirrhosis and hepatocellular carcinoma: implication of HBx in upregulation of COX-2. Mod Pathol. 2004;17:1169-79.

7. Ansara AJ, Nisly SA, Arif SA, Koehler JM, Nordmeyer ST. Aspirin dosing for the prevention and treatment of ischemic stroke: an indication-specific review of the literature. Ann Pharmacother. 2010:44:851-62.

8. Johnson ES, Lanes SF, Wentworth CE 3rd, Satterfield MH, Abebe BL, Dicker LW. A metaregression analysis of the dose-response effect of aspirin on stroke. Arch Intern Med. 1999;159:1248-53.

9. Peto R, Gray R, Collins $R$, et al. Randomised trial of prophylactic daily aspirin in British male doctors. Br Med J (Clin Res Ed). 1988:296:313-6.

10. Pignone $M$, Williams $C D$. Aspirin for primary prevention of cardiovascular disease in diabetes mellitus. Nat Rev Endocrinol. 2010;6:619-28.

11. Friis S, Sorensen HT, McLaughlin JK, Johnsen SP, Blot WJ, Olsen JH. A population-based cohort study of the risk of colorectal and other cancers among users of low-dose aspirin. Br J Cancer. 2003;88:684-8.

12. Huang WK, Chiou MJ, Yu KH, et al. The association between low-dose aspirin use and the incidence of colorectal cancer: a nationwide cohort study. Aliment Pharmacol Ther. 2013:38:432-9.

13. Lin CC, Lai MS, Shau WY. Can aspirin reduce the risk of colorectal cancer in people with diabetes? A population-based cohort study. Diabet Med. 2015; 32:324-31.

14. Flossmann E, Rothwell PM. Effect of aspirin on long-term risk of colorectal cancer: consistent evidence from randomised and observational studies. Lancet. 2007;369:1603-13.

15. Jiang $H Y$, Huang $T B, X u L$, et al. Aspirin use and lung cancer risk: a possible relationship? Evidence from an updated meta-analysis. PLoS One. 2015;10: e0122962.

16. Lapi $F$, Levi $M$, Simonetti $M$, et al. Risk of prostate cancer in low-dose aspirin users: a retrospective cohort study. Int J Cancer. 2016;139:205-11.

17. Jayaprakash V, Rigual NR, Moysich KB, et al. Chemoprevention of head and neck cancer with aspirin: a case-control study. Arch Otolaryngol Head Neck Surg. 2006;132:1231-6.

18. Pang $\mathrm{Q}$, Jin $\mathrm{H}$, Qu K, et al. The effects of nonsteroidal anti-inflammatory drugs in the incident and recurrent risk of hepatocellular carcinoma: a meta-analysis. OncoTargets Ther. 2017;10:4645-56.

19. Ma J, Cai Z, Wei H, Liu X, Zhao Q, Zhang T. The anti-tumor effect of aspirin: what we know and what we expect. Biomed Pharmacother. 2017:95:656-61.

20. Hwang IC, Chang J, Kim K, Park SM. Aspirin use and risk of hepatocellular carcinoma in a national cohort study of Korean adults. Sci Rep. 2018;8:4968

21. Aiolfi R, Sitia G. Emerging role of dual antiplatelet therapy in the prevention of hepatitis B virus-associated hepatocellular carcinoma. J Hepatocell Carcinoma. 2014;1:183-6.

22. Chen DS, Kuo GC, Sung JL, et al. Hepatitis C virus infection in an area hyperendemic for hepatitis B and chronic liver disease: the Taiwan experience. J Infect Dis. 1990;162:817-22.

23. Pol S, Lagaye S. The remarkable history of the hepatitis $C$ virus. Genes Immun. 2019:20:436-46. 
24. Ho CM, Lee $\mathrm{CH}$, Lee MC, et al. Comparative effectiveness of angiotensinconverting enzyme inhibitors and angiotensin II receptor blockers in chemoprevention of hepatocellular carcinoma: a nationwide high-risk cohort study. BMC Cancer. 2018;18:401.

25. Iannacone $\mathrm{M}$, Sitia $\mathrm{G}$, Isogawa $\mathrm{M}$, et al. Platelets mediate cytotoxic $\mathrm{T}$ lymphocyte-induced liver damage. Nat Med. 2005;11:1167-9.

26. Sitia G, Aiolfi R, Di Lucia P, et al. Antiplatelet therapy prevents hepatocellular carcinoma and improves survival in a mouse model of chronic hepatitis B. Proc Natl Acad Sci U S A. 2012;109:E2165-72.

27. Rivas-Estilla AM, Bryan-Marrugo OL, Trujillo-Murilo K, et al. Cu/Zn superoxide dismutase (SOD1) induction is implicated in the antioxidative and antiviral activity of acetylsalicylic acid in HCV-expressing cells. Am J Physiol Gastrointest Liver Physiol. 2012;302:G1264-73.

28. Rios-lbarra CP, Lozano-Sepulveda S, Munoz-Espinosa L, Rincon-Sanchez AR, Cordova-Fletes C, Rivas-Estilla AM. Downregulation of inducible nitric oxide synthase (iNOS) expression is implicated in the antiviral activity of acetylsalicylic acid in HCV-expressing cells. Arch Virol. 2014;159:3321-8.

29. Trujillo-Murilo K, Rincon-Sanchez AR, Martinez-Rodriguez H, et al. Acetylsalicylic acid inhibits hepatitis C virus RNA and protein expression through cyclooxygenase pathways. Hepatology. 2008;47:1462-72.

30. Yin $P$, Zhang L. Aspirin inhibits hepatitis $C$ virus entry by downregulating claudin-1. J Viral Hepat. 2016;23:62-4.

31. O'Byrne KJ, Dalgleish AG. Chronic immune activation and inflammation as the cause of malignancy. Br J Cancer. 2001:85:473-83.

32. Yu LX, Ling Y, Wang HY. Role of nonresolving inflammation in hepatocellular carcinoma development and progression. NPJ Precis Oncol. 2018;2:6.

33. Shin EC, Sung PS, Park SH. Immune responses and immunopathology in acute and chronic viral hepatitis. Nat Rev Immunol. 2016;16:509-23.

34. Sun P, Williams M, Nagabhushana N, Jani V, Defang G, Morrison BJ. NK cells activated through antibody-dependent cell cytotoxicity and armed with degranulation/IFN- $\gamma$ production suppress antibody-dependent enhancement of dengue viral infection. Sci Rep. 2019;9:1109.

\section{Publisher's Note}

Springer Nature remains neutral with regard to jurisdictional claims in published maps and institutional affiliations.

Ready to submit your research? Choose BMC and benefit from:

- fast, convenient online submission

- thorough peer review by experienced researchers in your field

- rapid publication on acceptance

- support for research data, including large and complex data types

- gold Open Access which fosters wider collaboration and increased citations

- maximum visibility for your research: over $100 \mathrm{M}$ website views per year

At $\mathrm{BMC}$, research is always in progress.

Learn more biomedcentral.com/submissions 